\title{
Oneness of Knowledge in Islamic Philosophy
}

\author{
Hassan Ajami \\ Arizona State University, Tempe, AZ, USA \\ Email: hassanajami25@yahoo.com
}

Received 20 May 2016; accepted 5 July 2016; published 8 July 2016

Copyright (C) 2016 by author and OALib.

This work is licensed under the Creative Commons Attribution International License (CC BY). http://creativecommons.org/licenses/by/4.0/

(c) $)$ E 0 Den Access

\begin{abstract}
Oneness of knowledge played a basic role in shaping many Islamic philosophical theories. It led many Muslim philosophers to aim at unifying different traditions of knowledge, paving the way for the development of their unique philosophical accounts. Only through unifying diverse traditions of knowledge and philosophy can one account for the oneness of knowledge, which states that the seemingly competing disciplines of research and sources of beliefs constitute one single and coherent set of knowledge. For example, the philosopher Al-Farabi attempted to unify Plato's idealism with Aristotle's realism. And the main reason behind his endeavor is to account for the belief that apparently distinct philosophical systems of beliefs which are in fact consistent and form a single body of knowledge. Similarly, one dominant school of Sufism, i.e. Islamic mysticism, endorses the idea of the oneness of the universe, which considers that all things are just one single entity. And the basic reason behind maintaining that all beings, including cultures and religions, are one is to express the belief that all kinds of knowledge are one. When all things or entities are one, they will provide a consistent set of beliefs, leading to the oneness of knowledge.
\end{abstract}

\section{Keywords}

\section{Al-Farabi, Plato and Aristotle}

Subject Areas: Philosophy

\section{Introduction}

One essential aim of Islamic philosophy is to unify different systems of beliefs. And Al-Farabi's philosophy is an excellent example of the Islamic philosophical process of unification. For instance, he attempts to unify Plato's idealism and Aristotle's realism into a coherent philosophical system. The tenth century Muslim philosopher Al-Farabi maintains that both Plato and Aristotle are speaking about the same truths and presenting the same knowledge. But they differ in the way they express themselves. For example, Plato uses more metaphors and symbols than Aristotle, while Aristotle, unlike Plato, relies more on clarification and classification of diverse facts and entities. According to Al-Farabi, since both Plato and Aristotle differ only with regard to how 
they express themselves, it follows that Plato's philosophy is coherent with Aristotle's philosophy. For Al-Farabi, both philosophies form a single unified and consistent philosophical paradigm. Al-Farabi doesn't deny the apparent differences between Plato's and Aristotle's philosophy. Yet he says that although Plato develops a unique account of idealism, while Aristotle defends material realism as an apparently opposing philosophical theory to Plato's idealism, still the philosophies of both are true and consistent. Plato holds that there are immaterial entities called Forms, which exist in an immaterial realm that separates from our material and actual world which we live in. According to Plato, the material particulars in our world gain their properties in virtue of the Forms. For example, these two tables are red because they participate in the Form of redness. Similarly, both of us are humans because we share and/or participate in the Form of humanity. But Aristotle provides a different philosophical account, according to which, the Forms are essences residing in our actual material world instead of existing in an immaterial realm that separates from the material universe. Aristotle presents realistic and/or materialistic explanations of how things in the actual world are formed. For instance, he claims that these two red tables are red because they share the essence of redness which actually exists in our material world. And, for him, a seed of a tree usually becomes a tree because it is potentially a tree and its potentiality is usually actualized, unless something prevents its actualization. Aristotle develops realistic explanations of the phenomena of our actual world in the sense that his explanations rely on what actually exists in the material world, such as essences and potentialities residing in our actual material universe, while Plato presents idealistic explanations of the phenomena of nature through relying on idealistic Forms existing in an immaterial realm.

Now, one basic argument developed by Al-Farabi in order to unify Plato's idealism and Aristotle's realism is the following: what is true is in fact true relative to a certain domain of inquiry, which describes and explains a specific realm of existence. From this perspective, Al-Farabi infers that idealism is true in the realm of metaphysics, i.e. it is true in the immaterial realm, while realism or materialism is true in the actual material world. Therefore, for him, idealism and realism are coherent, i.e. both Plato's and Aristotle's philosophy are coherent, leading to the oneness of knowledge [1]. Al-Farabi continues this process of unification of different fields of knowledge, and hence defend the oneness of knowledge when he describes the president of the virtuous city.

\section{Al-Farabi and the Virtuous City}

For Al-Farabi, the virtuous city is that which its members cooperate in order to achieve happiness. This virtuous city is successful in maintaining happiness through being harmonious and cooperative. It is the perfect city because its citizens live in cooperation, harmony and happiness. And it gains its perfection and happiness due to the fact that it is governed by a rational mind, exactly as the healthy body is governed by a rational intellect in virtue of which its bodily parts function in a harmonious manner. Al-Farabi holds that the president of the virtuous city should be a wise philosopher and a prophet at the same time. This is how Al-Farabi unifies between philosophy, i.e. independent rational reasoning, and religion, i.e. divine revelation.

Since the president of the virtuous city should be both a wise philosopher and a prophet, and consequently the philosopher and the prophet are just one person, it follows that the knowledge provided by a wise philosopher is consistent with, if not identical to, the knowledge provided by a prophet. Hence, the unification between these two seemingly diverse kinds of knowledge, namely knowledge of the philosopher and knowledge of the prophet, is successfully maintained. In addition, Al-Farabi wants the president of the virtuous city to be a wise philosopher and a prophet because any person becomes fully human, happy and successful through possessing knowledge and acting in light of it. And only the wise philosopher and prophet are able to present genuine knowledge, and hence maintain a successful and virtuous city. And as the virtuous city depends on the knowledge provided by the president, who is a philosopher and prophet at the same time, life itself depends on knowledge because, for Al-Farabi, to be alive means to possess knowledge. In fact, Al-Farabi analyzes life in terms of knowledge. For him, life is the possession of knowledge, and thus being fully alive amounts to having perfect knowledge [2]. Al-Farabi aims to account for the oneness of knowledge through unifying apparently diverse philosophies and sources of knowledge otherwise the world itself would be inconsistent. This shows the centrality of the oneness of knowledge in the formation of Al-Farabi's philosophy. If the different philosophies, such as Plato's and Aristotle's philosophy, and sources of knowledge, such as philosophy and divine prophecy, present distinct and competing kinds of knowledge, then they describe an inconsistent universe. And it is absurd to maintain that the world is inconsistent and contradictory. This is why Al-Farabi carries out his philosophical unification process through which he defends the oneness of knowledge and the consistency of the world. 


\section{Sufism, Ibn Arabi and Rumi}

Sufism is Islamic mysticism. There are different schools of Sufism. But they share some main beliefs and principles, such as calling for abandoning the material world, suppressing one's needs and desires, and going into a spiritual journey in order to experience the spiritual realm and be in the presence of God. One dominant Sufi school adds to these beliefs and principles some interesting convictions, such as the oneness of the universe, the oneness of humanity, and the oneness of religions. The oneness of the universe is the idea that all things are one, while the oneness of humanity means that all humans are just one human being. And the oneness of religions is the belief that all religions are one because they share a common essence, which emphasizes specific religious beliefs and duties, such as loving others and being just and merciful. This school of Sufism was developed by some great Sufis, such as Ibn Arabi and Jalal ad-Din Rumi. Ibn Arabi is a poet and philosopher who articulated the philosophical contents of Sufism in the sense that he presented the philosophical foundations and arguments supporting Sufism. In one of his poems, he says that his heart is accepting every Form and becoming one with every Form. Ibn Arabi mentions that his heart is accepting and becoming one with the field of the gazelles, the convent of priests, the Quran, and the Old Testament [3]. These poetic verses imply the ideas of the oneness of the universe and the oneness of religions. Ibn Arabi's heart is able to accept and become one with nature and all religions because all things in the universe, including religions, are one. He explains, in the same poem, why he endorses the oneness of the universe and the oneness of religions through stating that love is his religion and his creed. Now, since love is his religion and his creed, it is natural that he accepts and becomes one with nature and all religions, leading to believing in the oneness of the universe and the oneness of religions. Rumi expresses similar beliefs to those of Ibn Arabi. For instance, he declares, in one of his poems, that he is neither from the East nor from the West, he is neither from India nor from China or Arabia, and neither from earth, water, air or fire [4]. This indicates that all of the distinctions between humans, cultures, and entities, such as earth, water, air and fire, are not genuine distinctions, and this is why he is not from any of them. Hence, all humans, cultures and objects are one. The same poem implies that he transcended all of the false distinctions through not being from one single entity or place, and through not being imprisoned by one single religion. When someone becomes one with all religions and existents, one transcends everything, including seemingly diverse religions. This is why he also holds that he is neither Christian, nor Jew, nor Muslim.

One main reason behind the development of this school of Sufism is the belief in the oneness of knowledge. Since apparently different beliefs form a single and coherent set of knowledge, it follows that there should be certain mechanisms which guarantee the oneness and indivisibility of knowledge. And the best mechanism to ensure the oneness of knowledge is to maintain that all humans, cultures, religions and natural phenomena are just one indivisible entity. When all humans, cultures, religions and natural phenomena are one, beliefs derived from all religions, cultures, humans and natural phenomena should naturally form a consistent set of knowledge, leading the way for the endorsement of the oneness of knowledge. This is how believing in the oneness of the universe and the oneness of humanity and religions is the best method for articulating the oneness of knowledge.

All of this indicates that the ideas and principles of the oneness of the universe and the oneness of humanity and religions were developed in order to maintain the belief in the oneness of knowledge. Thus, the oneness of knowledge is the basic reason behind the development of the previous school of Sufism. And this is how the oneness of knowledge played an essential role in shaping the Arab-Islamic mind and culture, such that it led to the formation of major philosophical paradigms, such as Sufism in its previous form. According to this school of Sufism, if religions, humans, cultures and natural phenomena are not one, then they will produce inconsistent and contradictory beliefs about all of the existents, leading to the irrationality of the universe and human existence. This is why believing in the oneness of religions, humans, and cultures, and the oneness of the universe and knowledge, is the best method for rationalizing the universe.

\section{Mathematics and Science}

The unification process was carried out throughout the Islamic history, leading to great mathematical and scientific achievements. And this unification process aiming to unify diverse existents, such as physical objects, religions, cultures and fields of inquiry, was motivated by the belief in the oneness of knowledge. The ninth century Muslim mathematician Al-Khwarizmi unified Greek and Indian mathematical knowledge, which led him to invent Algebra. While the Greek mathematical tradition was based on the geometric method, the Indian mathematical tradition relied on the arithmetic method. But Al-Khwarizmi was successful in unifying both traditions, 
and thus paved the way for modern Algebra [5].

Now, if Al-Khwarizmi had not believed in the oneness of knowledge, he would have not unified different traditions of mathematical knowledge into a new and coherent mathematical paradigm. Hence, the oneness of knowledge was a main principle behind his invention of Algebra. Al-Khwarizmi rationalized the universe through unifying distinct mathematical traditions. This is because if the different mathematical traditions could not be transformed into a single and consistent mathematical set of knowledge, then they would have been contradictory. And thus, they would have been describing and explaining a contradictory universe. This is why the only way to account for a rational and consistent world is to unify diverse traditions of knowledge, such as the Greek and Indian traditions of mathematics.

From the same perspective, the eleventh century Muslim scientist Ibn Al-Haytham unified classical physics with mathematics, leading to his discovery of the scientific method. His mathematical-physical approach was the foundation of most of his scientific propositions. In his scientific inquiries, which concentrated on studying optics and vision, he relied on experimentation and controlled testing [6]. Yet if Ibn Al-Haytham had not believed in the oneness of knowledge, he would have not aimed to unify mathematics and physics into a single coherent scientific approach, paving the way for his invention of the scientific method. In this sense, the belief in the oneness of knowledge played a pivotal role in the Arab-Islamic culture, such that it led to great mathematical and scientific discoveries in addition to its essential role in the development of interesting philosophical theories.

\section{References}

[1] Al-Farabi, A.N. (2001) Book of Combining between the Opinions of the Two Wise Men. Arabic Edition, Dar Al Mashriq Publishing House, Beirut.

[2] Al-Farabi, A.N. (1995) The Views of the People of the Virtuous City. Arabic Edition, Al-Helal Publishing House, Beirut.

[3] Arabi, I. and Muhammad, A.A.A. (1978) Tarjuman Al-Ashwaq. Arabic Edition, Dar Sader Publishers, Beirut.

[4] Rumi, J.A.-D. (2015) Diwan Shams Tabriz. Arabic Edition, Dar Ninawa Publishing House, Damascus.

[5] Al-Khwarizmi, M.I.M. (2008) Al-Kitab Al-Mukhtasar fi hisab al-jabr wal-muqabala. Arabic Edition, Dar Byblion Publishing House, Byblos.

[6] Al-Haytham, I. and Al-Hasan, A.A. (1983) Kitab Al-Manazir. Arabic Edition, Al Majlis Al Watani lil Thaqafah wa al-Funun wa al-Adaab, Kuwait City.

\section{Warmly welcome your paper submission to OALib Journal!}

- Publication on a daily basis

- 9 subject areas of science, technology and medicine

- Fair and rigorous peer-review system

- Fast publication process

- Article promotion in various social networking sites (LinkedIn, Facebook, Twitter, etc.)

- Widely-targeted and multidisciplinary audience to read your research

Submit Your Paper Online: Click Here to Submit

Contact Us: service@oalib.com 